\section{Threat to solar mission}

\section{Washington}

European scientists could suffer directly from Mr Reagan's proposed budget cuts through a recommendation that the United States reduce its commitment to the international solar polar mission, a two-spacecraft programme run jointly by the National Aeronautics and Space Administration (NASA) and the European Space Agency (ESA).

Although no details of the reduced commitment have been officially announced, the White House is said to have suggested that NASA should stop work on its own spacecraft. This would effectively eliminate half of the project, and seriously reduce its scientific value, much of which depends on the simultaneous collection of data from the two spacecraft as they follow polar orbits around the Sun.

NASA and ESA officials are now discussing the implications of $\mathrm{Mr}$ Reagan's proposal, which could still be modified before the details of the new budget are announced on $10 \mathrm{March}$. The solar polar mission was threatened with termination by Congress last summer, but survived after vigorous intervention by the State Department and the Office of Science and Technology Policy.

Under the budget proposal submitted to Congress by President Carter last month, the two spacecraft would be launched from the space shuttle, using a modified Centaur launcher as a substitute for the delayed inertial upper stage, early in 1986.

David Dickson

including an end to grants to states to protect their coastal zones, a 50 per cent reduction in support of college research under the Sea Grants programme, and the deferment of the National Ocean Satellite System (NOSS).

As for the private sector, a firm belief that the federal government should not interfere with the mechanics of the marketplace is reflected in substantial cuts to the Department of Energy's research and development budget. These would eliminate many of the department's efforts to demonstrate the commercial potential of new energy technologies, such as synthetic fuels, coal liquefaction and solar energy; but the aim is to maintain a basic commitment to long-range research projects considered too expensive or too risky by the private sector.

Public reaction to the proposed cuts from the scientific community has so far been muted. This is partly because precise details of where the cuts will fall will not be announced until 10 March and partly because there is little at present to be gained in Washington by speaking out against massive cuts in federal expenditure. Privately, however, laboratory chiefs and university presidents are already pulling all the strings they can, both within Washington's scientific establishment and among their congressional allies, to protect their own research programmes.

Some may already have been effective. A proposal from $\mathrm{Mr}$ David Stockman, director of the Office of Management and Budget, to eliminate the National Aeronautics and Space Administration's Galileo mission to Jupiter was removed from the President's message to Congress. Given a decision to defer the Venus Orbiting Imaging Radar, this would have virtually wiped out all future planetary research at NASA's Jet Propulsion Laboratory in California, Mr Reagan's home state.

On other proposals, there are bitter fights in prospect. Most of the projects that Mr Reagan is proposing to defer have been argued for by the scientific community strong and hard. These include NASA's gamma-ray observatory (already approved for funding by Congress), the National Science Foundation's 25-metre millimetrewave radioastronomy dish and the NOSS satellite system.

Funding for space transportation systems will be maintained at a level adequate to cover the costs of the space shuttle, at the expense of slower development for Spacelab, and the rescheduling of space science flights - Galileo, for example, is likely to be shifted back from a 1985 to a 1986 launch. There will also be no funds for the solar electric propulsion system for which, in the absence of a Halley's comet mission, no applications have been approved.

At the National Science Foundation, budget restrictions will, as previously rumoured, be concentrated on programmes that are "narrowly focused or of less immediate priority" - such as innovation in small businesses and international scientific efforts - as well as on new initiatives in science and engineering education, and on research in the behavioural, social and economic sciences.

In contrast, there would be no reduction in the previously proposed 17 per cent increases for research in the mathematical and physical sciences, or the 20 per cent increase for engineering research. Both are considered by the new Administration to be "of relatively high importance to future technological advancement and to the long-term health of the nation".

In energy research, $\mathrm{Mr}$ Reagan is proposing a reduction of $\$ 40$ million in the $\$ 607$ million which had been suggested for basic energy sciences. Details of how this cut will be distributed are still being discussed. Most of it is likely to fall on highenergy physics, which accounts for twothirds of the total, and will suffer the delayed construction of new facilities.

Biomedical research has been left relatively untouched ; where the previous Administration had suggested a relatively modest 9 per cent increase for the National Institutes of Health (NIH), Mr Reagan is suggesting a slight reduction in both 1981 and 1982 funding that will reduce this to 6 per cent. Much of the saving would come from reduced payment to educational institutions for NIH research training, which the Administration says would eliminate the practice of paying more to an institution for a federally supported trainee than would be charged for those who are not federally supported.

The Administration says that even though its proposed new budget for NIH would not fully cover the projected inflation rate - and that real reductions below the present base will therefore have to be made across all NIH institutes - it is committed to maintaining a substantial number of new research awards. It is therefore likely to continue the previous Administration's strategy of focusing on competitive project grants, rather than programme grants or intramural research.

David Dickson

\section{UK nuclear energy \\ CEGB sheepish}

The British nuclear industry is outwardly unruffled by criticisms from the House of Commons Select Committee on Energy last week (Nature 19 February, p.621). The general response is that the committee has misunderstood many of the issues. The strongest reaction is to the committee's criticism of the government's 1979 statement on nuclear power, which the committee took to be a commitment to build one nuclear station a year for the coming decade. This, it is said, was never the intention, so that the committee's recommendation that each reactor should be judged on its merits is already part of public policy.

The Central Electricity Generating Board (CEGB), the organization most sharply criticized, was the most sheepish last week. There is plainly some foundation for the charge that it had not been forthcoming with up-to-date estimates of cost and electricity demand. On the complaint that nuclear power stations are 34 per cent more expensive to build in Britain than elsewhere, Mr Glynn England, chairman of the board, is to meet nuclear suppliers and subcontractors to find ways of cutting costs and improving productivity on nuclear plant sites.

Mr England does not, however, accept the committee's view that the ordering of a second pressurized water station should be delayed for six or more years until the first, now being designed for the Sizewell site, is operating. Detailed studies and a public inquiry should provide enough information for the board to decide whether subsequent reactors should be based on pressurized water (as at Sizewell) or gas-cooled technology.

The Nuclear Installations Inspectorate also says that the committee has misunderstood its role. In particular, it 